\title{
Numerical modelling of the fatigue crack shape evolution in a shot-peened steam turbine material
}

C. You ${ }^{a^{*}}$, B.Y. He ${ }^{a}$, M. Achintha, ${ }^{a, b}$, P.A.S. Reed ${ }^{a}$

a Engineering Materials Group, Faculty of Engineering and the Environment, University of Southampton, Highfield, Southampton SO17 1BJ, UK

b Infrastructure Group, Faculty of Engineering and the Environment, University of Southampton, Highfield, Southampton SO17 1BJ, UK

\section{Abstract}

In this study, the short crack initiation and growth behaviour in a notched sample under low-cycle fatigue (LCF) was investigated in a low-pressure steam turbine material. Different crack initiation mechanisms and crack shape evolution processes were experimentally observed in samples subjected to different surface treatments: polished, T0 (industrially applied shot peening process) and T1 (a less intense shot peening process). To better understand the effects of shot peening on fatigue, a 3D finite element ( $\mathrm{FE}$ ) model was developed to investigate the interaction between crack growth and the effects induced by shot peening. Firstly, residual stress redistribution caused by both mechanical loading and the presence of a crack was numerically investigated. This model was also used to successfully predict the differences in crack shape evolution between varying surface conditions, and quantified the retardation of short crack growth behaviour resulting from shot peening. Finally, the 3D model introduced in this study was compared with a previously developed 2D model with plane strain assumptions to demonstrate the limitation of the 2D model in simulating the crack growth behaviour, and to emphasise the importance of taking the 3D crack shape into account when evaluating the short crack growth behaviour.

Keywords: Shot peening, residual stress, short crack, crack shape, finite element modelling

\section{Introduction}

Shot peening is an effective surface treatment method used to improve the fatigue resistance of metallic components, particularly in regions with stress concentration features, such as the fir tree interface in steam turbine systems [1-3]. During the shot peening process, the surface of the workpiece is bombarded by a stream of small spherical shots at high velocities acting as tiny peening hammers, producing inhomogeneous plastic deformation near the surface. This process typically induces increased surface roughness, strain hardening and compressive residual stresses (CRS) within the surface layer [4]. Many investigations have focused on the effect of shot peening on fatigue

\footnotetext{
* Corresponding author. Tel.: +44 (7) 448196419

Email address: c.you@soton.ac.uk (C. You)
} 
behaviour in different material systems such as steel [1, 3, 5-7], aluminium [8-13], titanium [8], magnesium $[8,14,15]$ alloys and nickel-based superalloys $[16,17]$. It can be generally concluded that the roughened surface after the peening treatment may accelerate crack initiation [8], on the other hand, the CRS and strain hardening effects can compensate for this by deferring the short crack onset and propagation process $[5,9,10,14,18]$. Recent reviews $[19,20]$ have detailed at some length the effects of shot peening on fatigue by discussing the interaction between the shot peening induced effects (i.e. surface roughness, CRS and strain hardening) and service conditions. Although the effects of shot peening on fatigue have been well documented, it is still unclear how to accurately quantify the benefits of shot peening in prolonging fatigue life, which impedes the development of a less conservative lifing approach exploiting the benefits of shot peening but with sufficient safety margins. Many researchers have systematically studied the residual stress relaxation behaviour in shot-peened specimens during fatigue loading both experimentally and numerically $[2,6,7,11,15,16,21-23]$. It was found that the residual stress distribution generally reached a stabilised state after a logarithmic relaxation process during fatigue loading. Most studies have related the improvement in fatigue life by shot peening to the extent of the remaining CRS field after residual stress relaxation, and tried to predict the fatigue life utilising some stress- or strain-based approaches without explicitly considering the crack initiation and propagation behaviour $[6,7,24,25]$. These approaches have been demonstrated to be effective and efficient, particularly in the high-cycle fatigue (HCF) regime. However, in the low-cycle fatigue (LCF) regime where the relief of CRS is typically more significant, the competition between the effects of surface defects (introduced by shot peening or the manufacturing process) and CRS on short crack growth becomes more pronounced [18, 26-30]. This leads to diminished benefits of shot peening in improving fatigue life, compared with the HCF regime. Sometimes shot peening may further lead to a degraded fatigue life due to the dominant effects of surface defects on accelerating crack initiation and early propagation [27-30]. Hence, in the LCF regime, the stress- and strain-based approaches may result in non-conservative life prediction, which is unacceptable [24]. Under such circumstances, in addition to understanding the mechanism of the retarded short crack growth realised by shot peening, quantifying this retardation is a prerequisite before developing appropriate lifing methodologies.

To date, most of the quantitative studies on short crack growth behaviour influenced by shot peening (or other surface treatments resulting in CRS, such as laser shock peening) have relied on analytical $[12,13]$ and finite element (FE) $[17,31,32]$ modelling. According to these analyses, the CRS-induced crack closure, which reduces the effective stress intensity factor (SIF) range, $\Delta K_{e f f}$, has been deemed as the main factor leading to the delayed short crack growth behaviour. However, the effects of shot peening on crack shape have rarely been considered in previous work, due to the lack of reliable 
quantitative experimental data describing crack propagation in the bulk of the material to support relevant modelling work. Therefore, most studies assumed a constant crack shape during crack growth [13] or simulated through-thickness cracks as a simplification of the reality [17, 32].

He et al. $[18,33]$ recently reported a significant discrepancy between the short crack shape evolution in polished and shot-peened notched samples made of a 9-12\% $\mathrm{Cr}$ steel (a steam turbine material). This discrepancy was closely related to the shot peening process and the microstructure of the material. This implied the necessity of taking the crack shape effects into account when evaluating the influence exerted by shot peening on short crack growth. Hence, the current study utilised a 3D FE model containing a semi-elliptical crack to investigate how shot peening affects crack shape evolution, and how significant it is in life assessment. Both the crack size and crack shape evolution have been reasonably well predicted based on the modelling results. The FE model applied in this study was developed from a previous FE model which has been demonstrated to be effective in simulating residual stress relaxation [22]. The same material as He et al $[18,33]$ has been selected and the reported experimental data have been used as validation of the present modelling work. The current work is also relevant due to the relatively few investigations focusing on steam turbine materials subjected to shot peening compared with other material systems [1-3].

\section{Experiments}

\subsection{Material and specimen}

The material under investigation is FV448, a 9-12\% $\mathrm{Cr}$ tempered martensitic steel which is representative of the type of material used in low-pressure turbine blades. This material is typically austenitised at $1150{ }^{\circ} \mathrm{C}$, oil quenched, tempered at $650{ }^{\circ} \mathrm{C}$ and then air cooled. The main monotonic tensile properties of the materials are shown in Table 1. The other mechanical properties, microstructure and composition of this material have been detailed in [21]. In this study, a U-notched specimen (stress concentration factor, $K_{t}=1.58$ ) representing the fir tree root geometry of a turbine blade has been used. The dimensions of this specimen are shown in Fig. 1.

Table 1: Monotonic tensile properties of FV448.

\begin{tabular}{ccccc}
\hline$\sigma_{0.2} / \mathrm{MPa}$ & $\sigma_{U T S} / \mathrm{MPa}$ & Strain $(\%)$ at failure & $E / \mathrm{MPa}$ & $v$ \\
\hline $806 \pm 6$ & $987 \pm 9$ & $12 \pm 3$ & $201.3 \mathrm{E}+03$ & 0.3 \\
\hline
\end{tabular}






Fig. 1: Dimensions of the U-notched specimen

Samples to be shot peened were all ground to achieve an initial surface roughness of $R_{a}<0.8 \mu \mathrm{m}$, meeting the industrial machined component (and pre-peen) specification. Some ground samples were polished to remove the grinding marks and the associated residual stress field, with a surface finish of $\pm 1 \mu \mathrm{m}$. Both ground and polished samples were used in the baseline tests as a comparison with the shot-peened condition. Two shot peening treatments were investigated in this study. MI230R 13A 200\% (intensity: 13A, coverage: $200 \%$, shot diameter: $0.58 \mathrm{~mm}$ ), labelled as T0, was chosen as the baseline shot peening treatment since it was industrially applied to steam turbine blades. Another process, MI110R 04A 200\% (intensity: 4A, coverage: $200 \%$, shot diameter: $0.28 \mathrm{~mm}$ ), labelled as T1, was considered as a comparison. All the shot peening treatments were carried out by Metal Improvement Company, Derby Division.

Experimental residual stress measurements were carried out at the notch root using X-ray diffraction (XRD), accompanied by incremental layer removal via an electro-polishing process to obtain the stress profile into the depth. Details regarding this measurement have been elaborated in $[3,22]$ so are not repeated here. The residual stress distributions caused by the T0 and T1 process at the notch root are shown in Fig. 2, illustrating that the TO process results in a greater and deeper compressive residual stress layer than the T1 process. In addition, the plastic strain caused by shot peening has been measured using an electron back-scatter diffraction (EBSD) based approach [21]. The results are shown in Fig. 3, illustrating more significant strain hardening effects caused by the T0 process than the T1 process. 


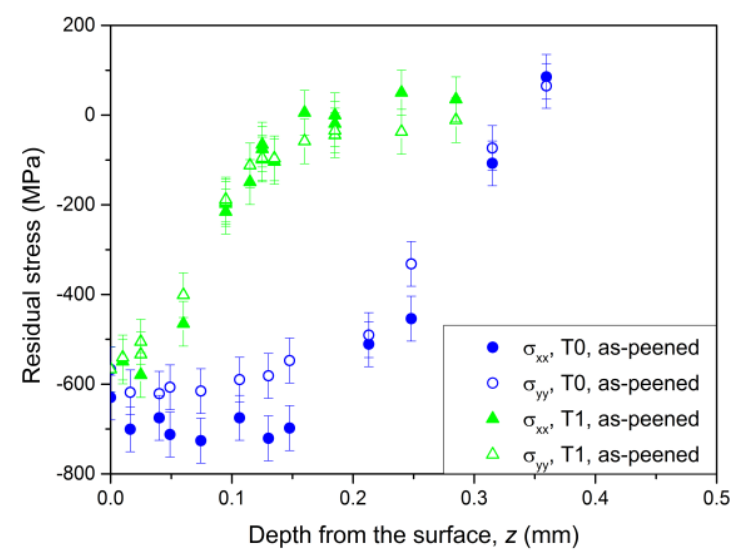

Fig. 2: The compressive residual stress distributions in two orthogonal directions ( $\sigma_{x x}$ and $\sigma_{y y}$ ) caused by the TO and T1 shot peening processes at the notch root (the data for the TO condition were reproduced from Soady et al. [3]).

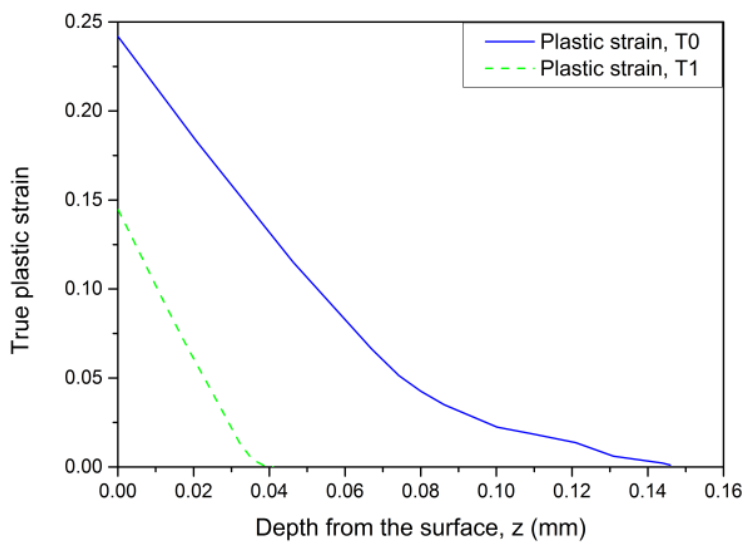

Fig. 3: Predicted true plastic strain distributions caused by the TO and T1 shot peening [21].

\subsection{Fatigue tests and results}

All the fatigue tests were carried out at room temperature with a sinusoidal waveform and a frequency of $20 \mathrm{~Hz}$ using a servo hydraulic Instron 8502. The notched specimens were loaded under 3-point bend with a load ratio $R=0.1$. The true longitudinal strain range, $\Delta \varepsilon_{x x}$, experienced in the centre at the notch root, was estimated using an FE model developed by the authors [22], allowing for the effects of both compressive residual stresses and strain hardening induced by shot peening. The strain-life $\left(\Delta \varepsilon_{x x}-N_{f}\right)$ plots for different surface treatments (i.e. ground, polished, T1 and T0 shot peening) are presented in Fig. 4. Compared with the un-peened condition, it can be seen that the T0 process contributes to life improvement at all $\Delta \varepsilon_{x x}$ levels. By contrast, the T1 process gives much less benefit in life improvement when $\Delta \varepsilon_{x x}>0.65 \%$. 


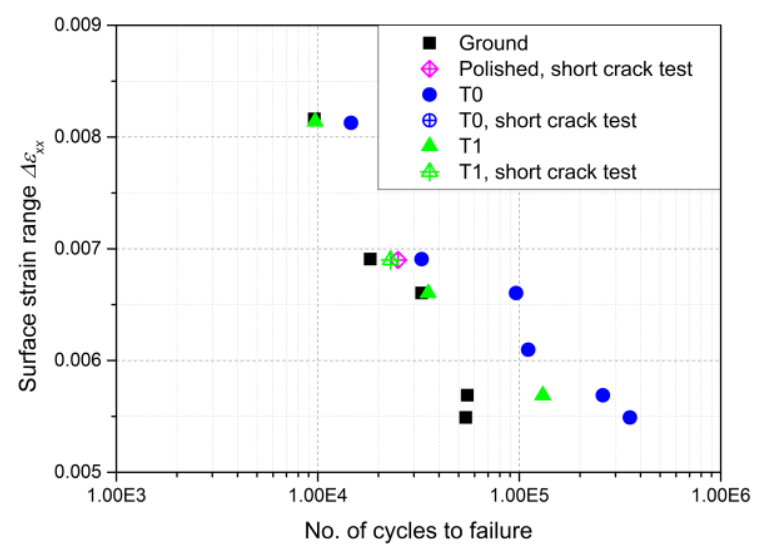

Fig. 4: Strain-life comparison between the notched samples with different surface treatments (fatigue life data reported in He et al. [18] were replotted using the FE model incorporating shot-peening effects).

As indicated in Fig. 4, short crack tests have been carried out at $\Delta \varepsilon_{x x}=0.69 \%$ for specimens treated by polishing, T0 and T1 shot peening respectively. Replicas have been used to track the surface crack (2c) evolution at the notch root. Relevant details are elaborated in [18]. The obtained results are reproduced in Fig. 5, demonstrating a more significantly delayed short crack growth behaviour caused by the T0 process than the T1 process.

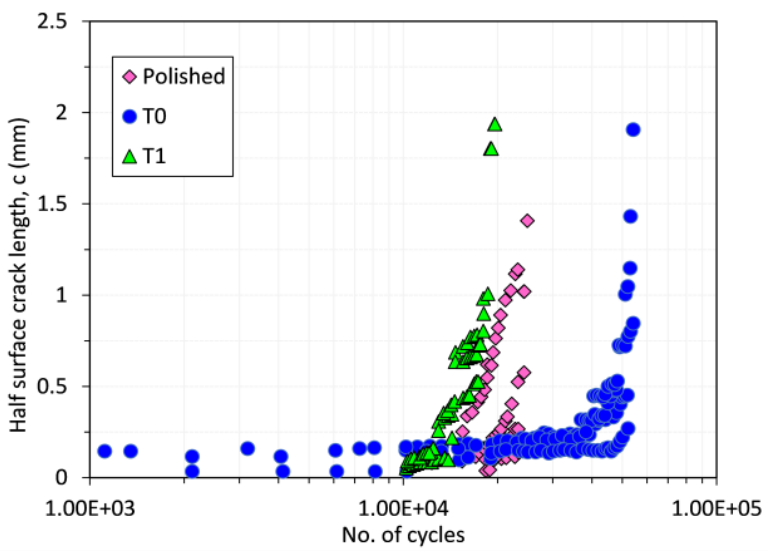

Fig. 5: Surface crack evolution in the polished, TO and T1 shot peening conditions [18].

In addition, the evolution of crack shape at $\Delta \varepsilon_{x x}=0.69 \%$ has also been systematically determined based on experimental observations in a number of notched samples, details regarding the experimental methodologies are published in [18]. The crack aspect ratio, which was used as a representation of the crack shape, was defined as $a / c$, where $a$ was the depth of the crack and $c$ was half the surface crack length, as illustrated in Fig. 6. Relevant experimental results reported in [18] are reproduced in Fig. 7 , showing that cracks initiated with a relatively high $a / c(a / c=1.2)$ in polished samples compared with the TO condition, whereas much shallower cracks $(a / c=0.2)$ were observed at the very beginning. In the T1 condition, both crack initiation aspect ratios were observed. This difference found between different surface conditions can be shown by Fig. 8 , which shows the morphology of some initial cracks obtained using a scanning electron microscope (SEM) on the 
fracture surface [18, 34]. As can be seen in Fig. 8(a), a typical feature in the polished condition is that the inclusions distributed normal to the notch root surface seem to facilitate crack initiation in the depth direction, resulting in high initial $a / c$. While in the T0 condition shown in Fig. 8(b), there is no clear evidence of the effects of inclusions. Instead, cracks initiated from high stress concentration areas caused by surface roughness or crack-like surface defects lying at the bottom of the peened dimples, resulting in low initial $a / c$. In the T1 condition, a mixed crack initiation mechanism (both modes) was observed, as can be seen in Fig. 8(c)(d). In Fig. 7, data for all three surface conditions begin to merge at $a=0.1 \mathrm{~mm}$, achieving a stabilised crack shape with $a / c=0.8-0.9$, apart from some data in the TO condition where crack coalescence frequently occurred as the cracks grew. According to previous research $[35,36]$, the crack shape evolution process, despite varying with the initial crack configuration, tends to develop asymptotically to a preferred equilibrium state where $a / c$ converges to a stable range. This is consistent with the general trend of the experimental data shown in Fig. 7 (apart from the data resulting from crack coalescence). However, the mechanism behind the experimental observations in terms of the shot peening effects is still less clear, although an intensive discussion is given in [18].

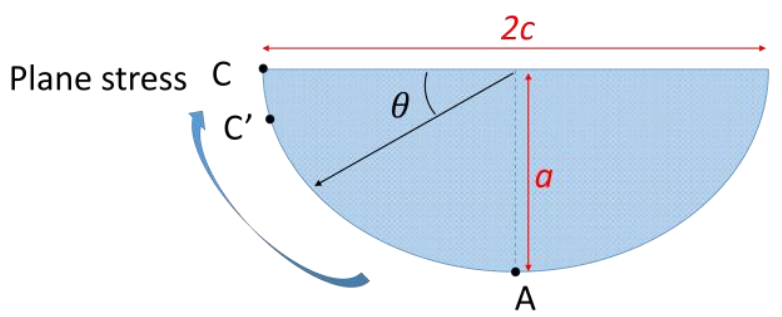

Plane strain

Fig. 6: Schematic diagram showing the definition of the crack aspect ratio (a/c) based on surface crack length (2c) and the depth of the $\operatorname{crack}(a)$.
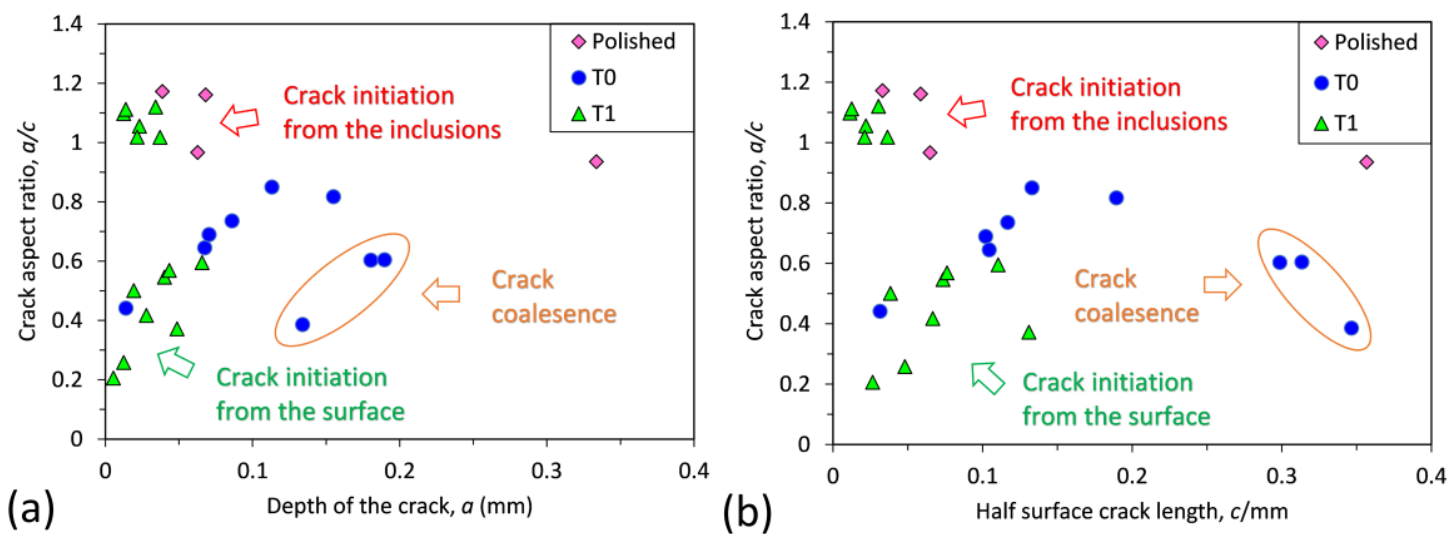

(b)

Fig. 7: Crack aspect ratio a/c based on the fatigue crack morphology on fracture surface in polished, TO and T1 conditions: (a) $a / c$ vs $a$ and (b) a/c vs c [18]. 

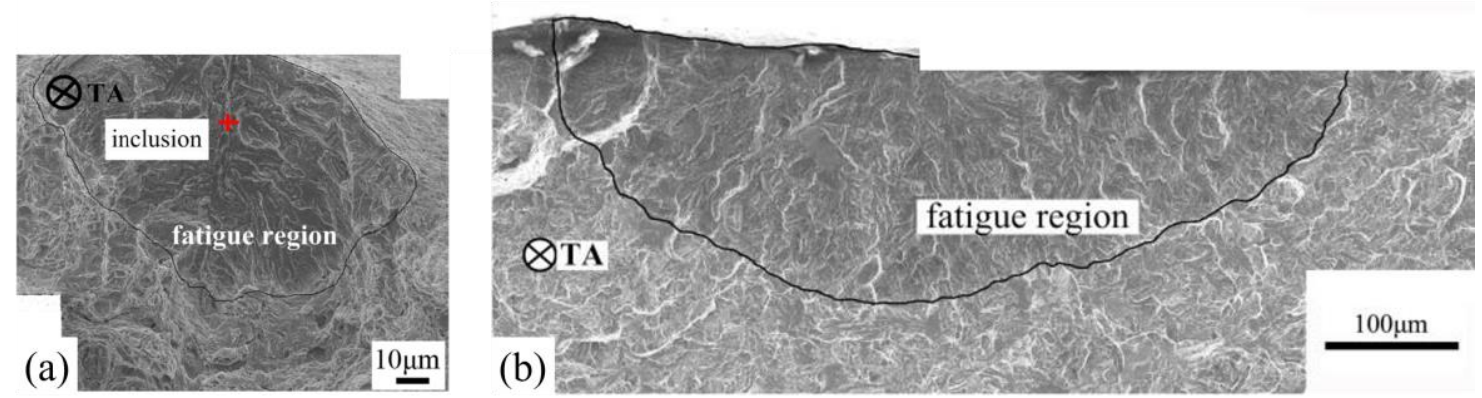

(b)
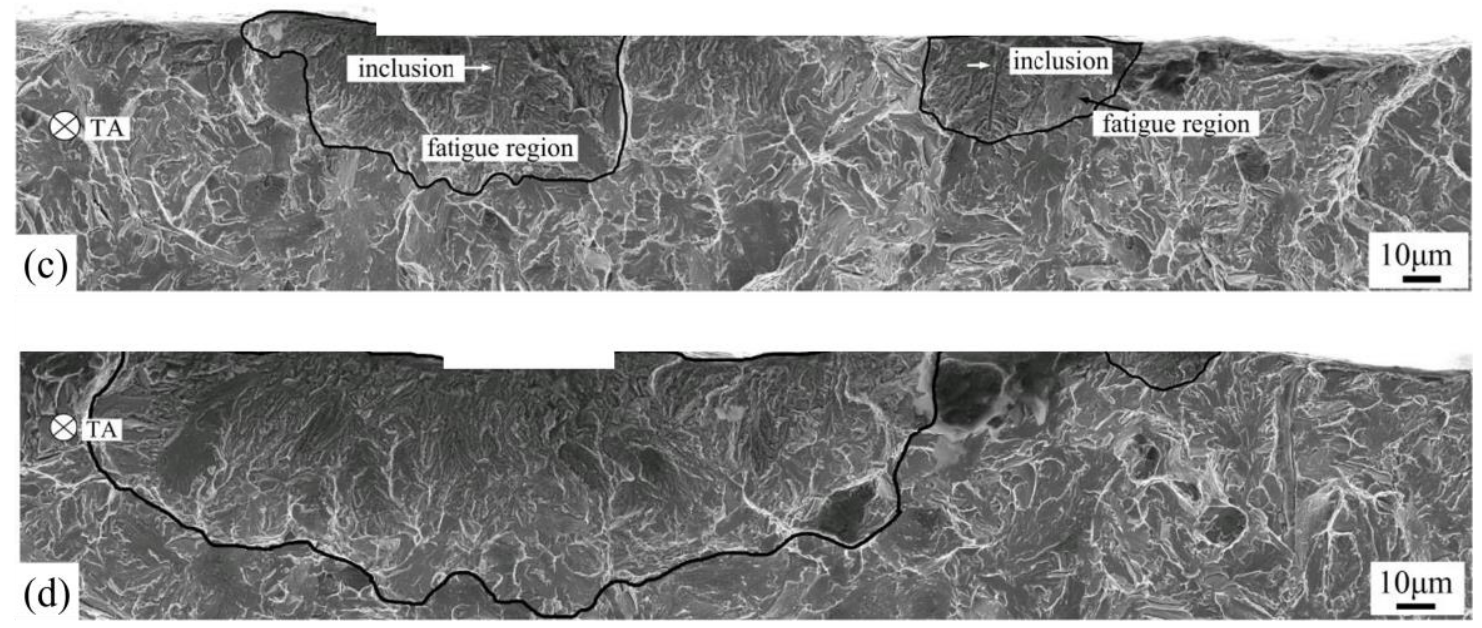

Fig. 8: SEM micrographs of cracks with labelling in the (a) polished, (b) TO and (c)(d) T1 shot peening conditions, demonstrating the crack initiation mechanism $(a)(c)$ with and $(b)(d)$ without the effects of inclusions [18, 34].

\section{Modelling}

\subsection{FE model containing a crack}

A 3D FE model incorporating both the CRS and strain hardening effects induced by shot peening has been developed by the authors using ABAQUS/Standard (v6.13) [22]. A non-linear kinematic and isotropic hardening material model was applied to represent the mechanical properties of the material. The compressive residual stress field was reconstructed using the inverse eigenstrain method [37]. Modelling of the strain hardening effects was achieved by defining the initial condition (plastic strain caused by shot peening) of the material model at different depths, based on measurements from an electron back-scatter diffraction (EBSD) based approach [21]. This model has been demonstrated [22] to be accurate in predicting the residual stress relaxation behaviour in two orthogonal directions ( $\sigma_{x x}$ and $\sigma_{y y}$ ) after the first loading cycle (i.e. quasi-static loading).

In the current study, this FE model has been upgraded to study the short crack growth behaviour affected by shot peening. Owing to symmetry, a quarter of the notched sample depicted in Fig. 1 has been modelled by applying adequate symmetry boundary conditions. In order to be less time consuming, the complete model consisted of an intensely-meshed region near the notch root and a coarsely-meshed part for the rest of the geometry. A semi-elliptical crack has been introduced into the intensely-meshed region, as illustrated in Fig. 9. A surface-to-surface tie constraint was applied to 
the interface between the coarsely- and intensely-meshed parts to ensure the consistency of the displacement. To simulate crack closure, the contact between the two crack flanks have to be defined. However, only one crack flank was modelled in Fig. 9 due to the applied symmetry boundary conditions. Therefore, a rigid face was attached along the symmetry plane to prevent the penetration of the crack flanks due to the crack closure under CRS, as shown in Fig. 9(b). The contact between the crack face (i.e. the yellow-shaded area in Fig. 9) and the rigid face was assumed to be frictionless since only the mode I crack was considered in this study.

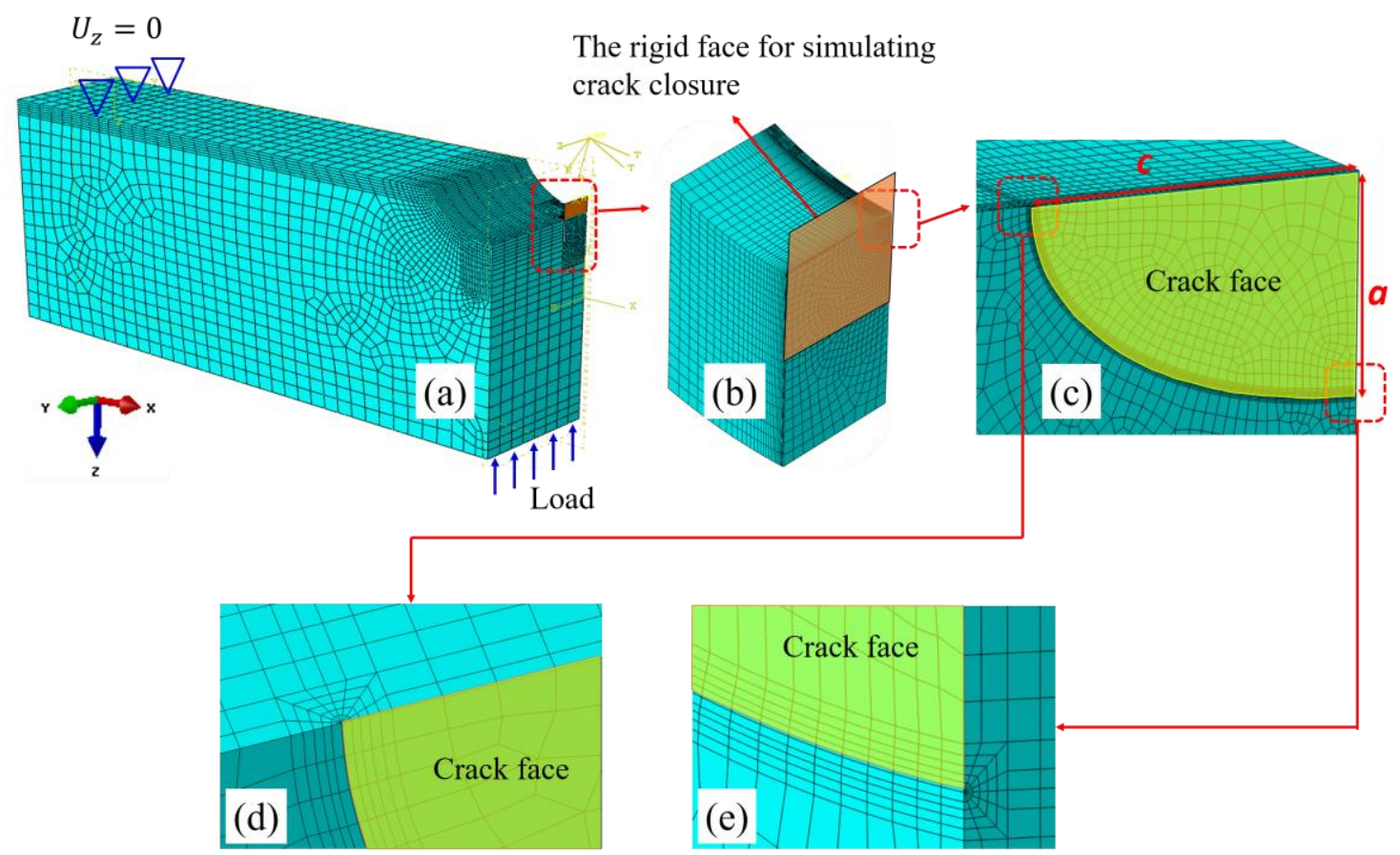

Fig. 9: Geometry and mesh for the (a) complete model, (b) the intensely-meshed part and (c) the contained crack, with detailed mesh pattern near (d) the surface point and (e) the deepest point of the crack; the crack face is shaded in yellow.

The crack front was meshed using 15-node 3D wedge elements (C3D15) and a spider web mesh pattern was applied around the crack front, as shown in Fig. 9(d)(e). The rest of the model was meshed using 20-node reduced integration brick elements (C3D20R). A mesh convergence analysis was carried out, according to which a transition of element size from $1 \mu \mathrm{m}$ along the crack front to $0.1 \mathrm{~mm}$ along the edges was implemented in the intensely-meshed region. In the coarsely-meshed region, the global mesh size was chosen to be $0.5 \mathrm{~mm}$, with relatively refined meshes (element size: $0.1 \mathrm{~mm}$ ) near the top surface, which was deemed sufficient to obtain accurate results without huge computational costs. The same FE model (without incorporating shot peening effects) has also been used in the present numerical study, representing the baseline polished condition (referred to as the "un-peened" condition in the modelling work).

\subsection{Residual stress redistribution}


In order to obtain the redistributed residual stress field caused by cyclic loading, the introduced crack was initially deactivated by applying symmetry boundary conditions on the crack face. Residual stress redistribution was simulated by applying one cycle in the model, following the procedure elaborated in [22]. The modelling results at $\Delta \varepsilon_{x x}=0.69 \%$ are shown in Fig. 10 , which have been experimentally validated as reported in [22]. From Fig. 10, it can be seen that the first cycle results in a CRS layer near the surface in the un-peened condition, and extends the depth of the original CRS profile in the T1 and TO conditions to $0.4 \mathrm{~mm}$. In addition, no clear CRS relaxation is observed in the TO condition and the CRS in the T1 condition is even enhanced after the first cycle. In fact, this phenomenon is not surprising in the 3-point bend case: the inhomogeneous plastic deformation generated by the bending process itself develops a CRS layer after unloading as a result of the constraint exerted by the elastically deformed material beneath. This process tends to be more significant in the notched geometry and compensates for any CRS relief occurring in the loading $\left(\sigma_{x x}\right)$ direction [22]. The predicted residual stress distribution after the first cycle was deemed to be the stabilised residual stress state, because it has been experimentally demonstrated that residual stress relaxation (or redistribution) mainly took place during the quasi-static stage (i.e. the first cycle), especially in the notched case $[3,15,29]$.

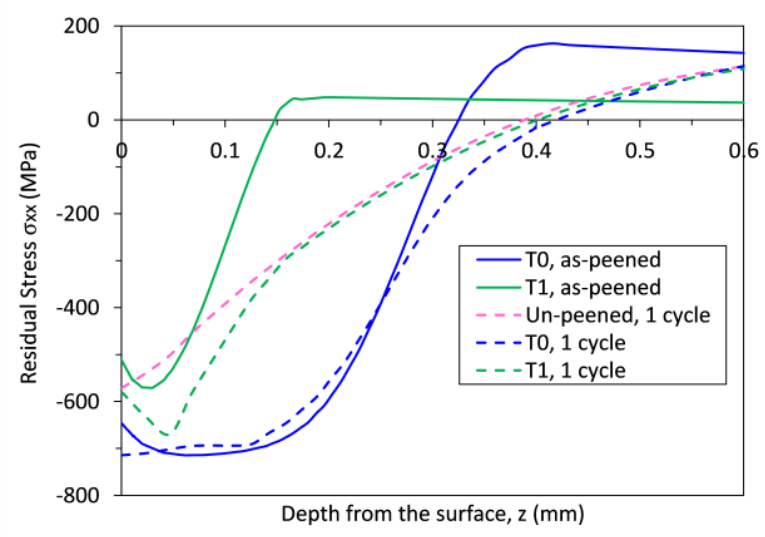

Fig. 10: FE-predicted residual stress $\left(\sigma_{x x}\right)$ redistribution caused by external loading (one cycle).

After obtaining the stabilised residual stress state, the crack was activated by removing the boundary conditions applied on the crack face. Then, the interaction between the residual stresses and the presence of a crack was investigated by applying an additional loading cycle in the model. Four cracks with varying sizes $(a=0.01,0.1,0.2$ and $0.4 \mathrm{~mm})$ and with the same $a / c(a / c=0.8)$ were modelled to elucidate the effects of crack advance on the redistribution of residual stresses.

The modelling results for the un-peened, T0 and T1 shot peening conditions are shown in Fig. 11(a) (b) and (c) respectively. The residual stress profiles shown in Fig. 10 are also included in Fig. 11, as baseline profiles. It can be seen from Fig. 11 that the crack results in a greater compressive area near the crack front, compared with the baseline profiles. However, in areas further from the crack tip, the residual stress field is relatively stable, being much less affected by the presence of the crack, as long as the 
crack front is still confined within the main CRS field. This can be more intuitively illustrated by the contour plots on the $x-z$ plane at the notch root for the TO condition, as shown in Fig. 12 (similar situations were observed in the un-peened and T1 conditions). This phenomenon is due to the plastic deformation caused by the crack being very localised and unable to significantly remove the overall misfits that are responsible for the original residual stress. This conclusion is consistent with the reported experimental observation in a laser shock peened specimen under LCF [38]. Hence, although crack growth was not directly simulated as a continuous process in this study, the predicted residual stress fields related to varying crack lengths were deemed reliable. It is also noteworthy from Fig. 11 that the size of the crack-affected zone increases when the crack becomes longer; from $0.02 \mathrm{~mm}$ at $a$ $=0.01 \mathrm{~mm}$ to $0.15 \mathrm{~mm}$ at $a=0.4 \mathrm{~mm}$. This can be explained by the broadening size of the plastic zone ahead of the crack front as the crack grows longer.

The effects of different $a / c$ on residual stress redistribution were found to be limited compared with the effects of $a$. This can be reflected in Fig. 13, which demonstrates that different $a / c$ (at fixed $a$ ) only result in a small variance of the residual stress ahead of the crack front, without significantly affecting the overall residual stress distribution. Hence, the effects of $a / c$ are not further discussed here.

The results for $a=0.01,0.1$ and $0.4 \mathrm{~mm}$ displayed in Fig. 11 are replotted in Fig. 14, to examine the range of shot peening effects. When $a=0.01 \mathrm{~mm}$, it can be seen clearly that the main favourable CRS in both the T0 and T1 conditions remains. When the crack grows to $a=0.1 \mathrm{~mm}$, the benefits of the T1 process over the un-peened condition in terms of CRS are completely removed, while the T0 condition still maintains significant benefits until the crack penetrates through the whole CRS field at $a=0.4 \mathrm{~mm}$. This analysis demonstrates that the effects of the T1 process are merely confined within a depth of $0.1 \mathrm{~mm}$. By contrast, the TO process more effectively delays short crack growth by extending the working depth of the CRS to nearly $0.4 \mathrm{~mm}$. 


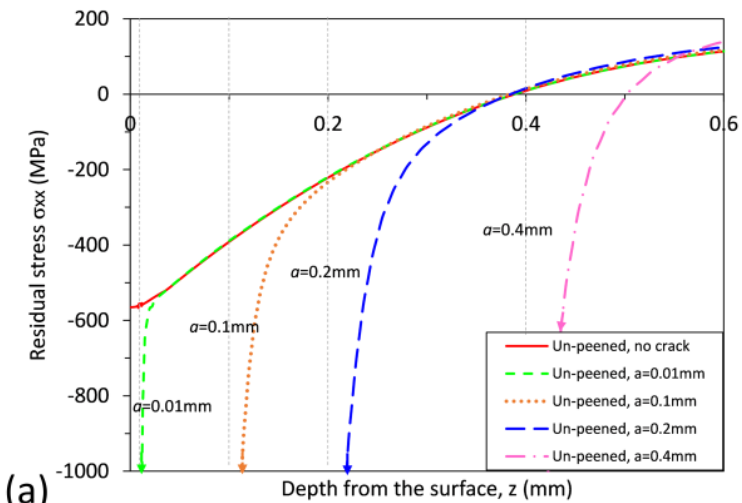

(a)

Depth from the surface, $z(\mathrm{~mm})$

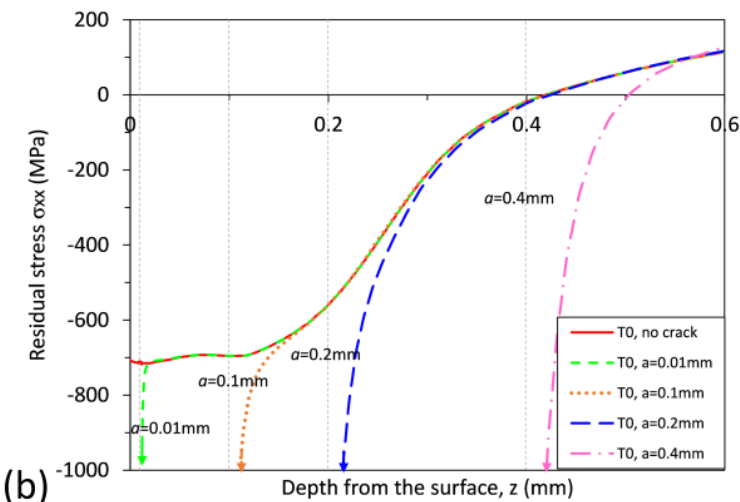

(b)

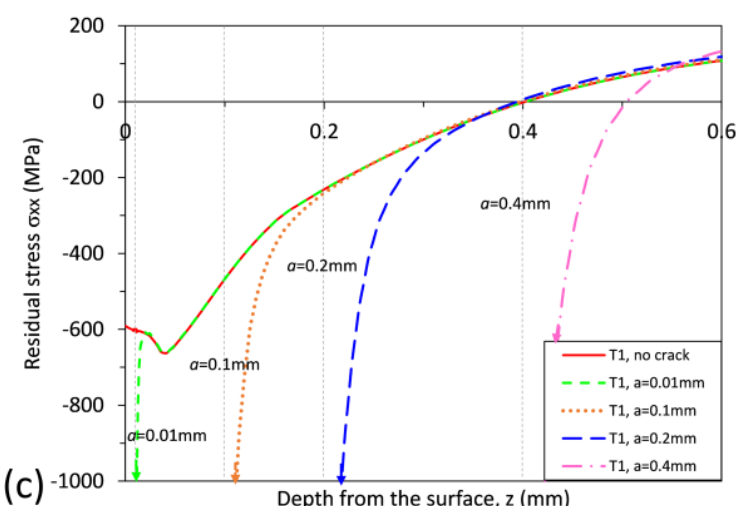

Fig. 11: Residual stress $\left(\sigma_{x x}\right)$ redistribution ahead of the crack caused by crack advance $(a=0.01,0.1,0.2$ and $0.4 \mathrm{~mm}, a / \mathrm{c}=$ 0.8 ) in the (a) un-peened, (b) TO and (c) T1 shot peening conditions.


Fig. 12: Contour plots of the residual stress $\left(\sigma_{x x}\right)$ field in the TO shot peening condition with crack advancing. 



(b)

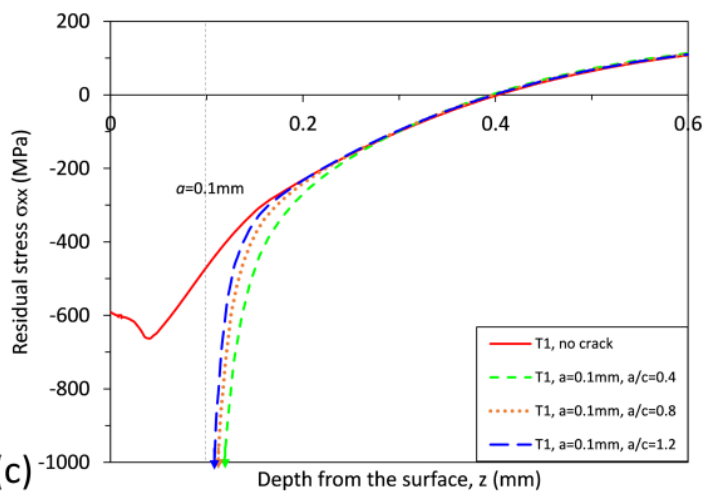

Fig. 13: Residual stress $\left(\sigma_{x x}\right)$ redistribution ahead of the crack caused by crack advance $(a=0.1 \mathrm{~mm}, a / c=0.4,0.8$ and 1.2$)$ in the (a) un-peened, (b) TO and (c) T1 shot peening conditions.

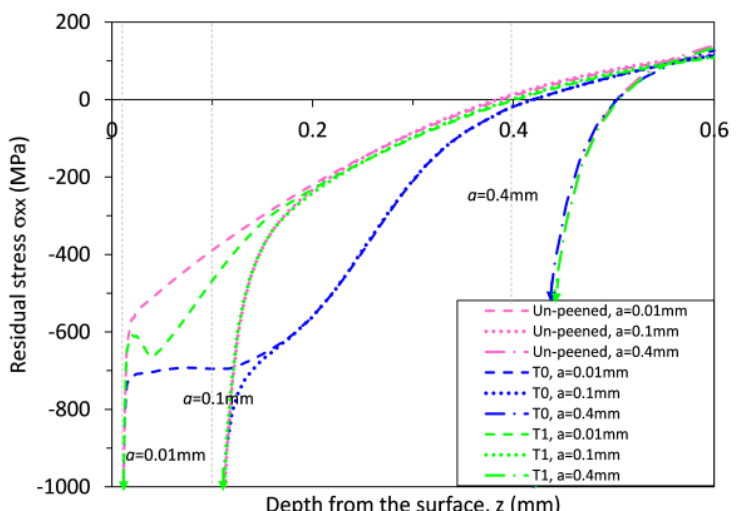

Fig. 14: Comparison between the residual stress $\left(\sigma_{x x}\right)$ redistribution ahead of the crack caused by crack advance in the unpeened, TO and T1 shot peening conditions. 


\subsection{Prediction of the crack shape $(a / c)$ evolution}

Prediction of the changing position of the crack front during fatigue loading is a key issue in predicting the crack shape evolution. Since the crack shape was assumed to be semi-elliptical in this study, only the position of the surface point and the deepest point on the crack front are required to describe the crack shape. As indicated in Fig. 6, a transition from the plane stress prevailing condition at the surface point (point $\mathrm{C}$ ), to the plane strain prevailing condition at the deepest point (point $\mathrm{A}$ ) generally exists along the crack front, which needs to be considered when evaluating the crack driving force [39-42]. According to the literature, numerical values of the crack driving force at point $\mathrm{C}$ should be treated cautiously due to two reasons: Firstly, intersection between the crack front and the free surface tends to result in a change of the power of the stress singularity at point $C$, where the assumption of the SIF in linear-elastic fracture mechanics (LEFM) is invalid [43, 44]; secondly, the plasticity-induced crack closure (PICC) effect is more pronounced at the free surface than in the bulk material due to the plane stress state at the surface, which may reduce the surface crack growth rate and potentially leads to a front-turning-inward phenomenon, hampering accurate characterisation of the crack driving force $[40-42,45,46]$. To overcome this difficulty, a point near the free surface on the crack front (i.e. point $C^{\prime}$ in Fig. 6) was selected instead of point $C$. In contrast to identifying point $C^{\prime}$ as the first point near the surface, which has been widely used in other modelling $[43,47]$, in this work the position of point $C^{\prime}$ was determined with respect to the plastic deformation along the crack front. As illustrated in Fig. 15 , point $C^{\prime}$ is the transition between two distinct types of plastic zone: the plastic zone with relatively uniform size in the interior region where plane strain effects dominate, and the larger plastic zone near the surface region, where plane stress effects dominate. Similar plastic zone distributions along the crack front have been obtained in $[40,41]$, and it was found that the larger plastic zone near the surface reasonably accounted for the PICC phenomenon. Therefore, selecting point $C^{\prime}$ is expected to simplify the crack modelling work by avoiding complex modelling of PICC of the surface crack. According to the modelling work, the exact position of point $C^{\prime}$ varied between $3^{\circ}<\theta<20^{\circ}$ depending on the $a / c$ of the crack, which was little affected by the residual stress levels under investigation. The error of replacing $O C$ with $\mathrm{O}^{\prime} \mathrm{C}^{\prime}$ (Fig. 15) was within $5 \%$, regardless of the crack size and shape.

According to the literature, methods applied to predict crack shape evolution can generally be classified into two categories: One is the adaptive remeshing technique [36, 39, 42, 48, 49], which realises an automatic update of the mesh around the new crack front extended stepwise from an initially predefined crack, based on the FE-determined SIFs along the crack front. Another category is the analytical process based on closed-form solutions for SIF, which are usually calibrated using the FE-determined SIFs along the crack front for varying crack shapes and sizes $[35,44,50]$. The similarity 
between the two categories is that the crack extension during each cycle is commonly predicted using the Paris Law based on local SIF. The main difference is that the remeshing technique simulates crack growth as a coherent process. Therefore, the cumulative effects during crack growth, such as residual stress redistribution caused by crack advance, and the plastic wake left behind the crack front resulting in PICC, can be effectively considered in the modelling work. By contrast, the analytical method treats crack growth as numerous separate steps without inheriting additional effects from the previous cycle. In the current case, the stability of the residual stress field with crack advancing has been demonstrated (Section 3.2), and the effects of surface PICC (which tends to be much less significant with CRS [51]) have been avoided by using point $C^{\prime}$ instead of point C. Therefore, the analytical approach based on closed-form solutions is deemed reliable in the current study, and thus has been applied to simplify the modelling process. To achieve this, cracks with a range of sizes and shapes have been defined in the modelling work in the un-peened, T0 and T1 shot peening conditions; $a=0.01$, $0.05,0.1,0.15,0.2,0.3$ and $0.4 \mathrm{~mm}, a / c=0.2,0.3,0.4,0.6,0.8,1.0$ and 1.2 , the ranges of which were determined to cover the experimental observations shown in Fig. 7.



Fig. 15: Demonstration of the equivalent plastic strain (PEEQ) distribution along the crack front $(a=0.1 \mathrm{~mm}, a / c=0.8)$ in the un-peened condition.

The SIF values at point $A$ and $C^{\prime}$ were calculated from the J-integral supplied by ABAQUS using the plane strain assumption, as described by Equation 1 where $E$ is the Young's modulus and $v$ is the Poisson's ratio of the material. Although the conventionally defined J-integral becomes pathdependent in the residual stress field, a local path-independence can still be achieved near the crack tip as long as the mesh is fine enough, and the corresponding value of the J-integral can still accurately represent the crack driving force $[52,53]$. Based on this idea, the J-integral calculated based on the $6^{\text {th }}$ contour was used in the present study to determine the corresponding SIF. The effective SIF range $\left(\Delta K_{e f f}\right)$ during cyclic loading was used to characterise the crack growth behaviour, as defined by Equation 2, where $K_{\max }$ and $K_{\text {open }}$ represent the SIF at the maximum load and the crack opening load (the moment when the crack is fully opened) respectively. To appropriately determine $K_{\text {open }}$, the crack closure phenomenon caused by CRS was studied in the FE model by monitoring the contact force 
between the crack face and the rigid face. Fig. 16 shows that the values of the J-integral are zero at the minimum load due to partial closure of the crack, then slightly increase to a small positive value when the crack is fully opened, before rising up noticeably with increasing load. Hence, $K_{\text {open }}$ was approximated as zero in the current modelling work.

$$
\begin{aligned}
& K=\sqrt{\frac{E J}{1-v^{2}}} \\
& \Delta K_{\text {eff }}=K_{\text {max }}-K_{\text {open }}
\end{aligned}
$$
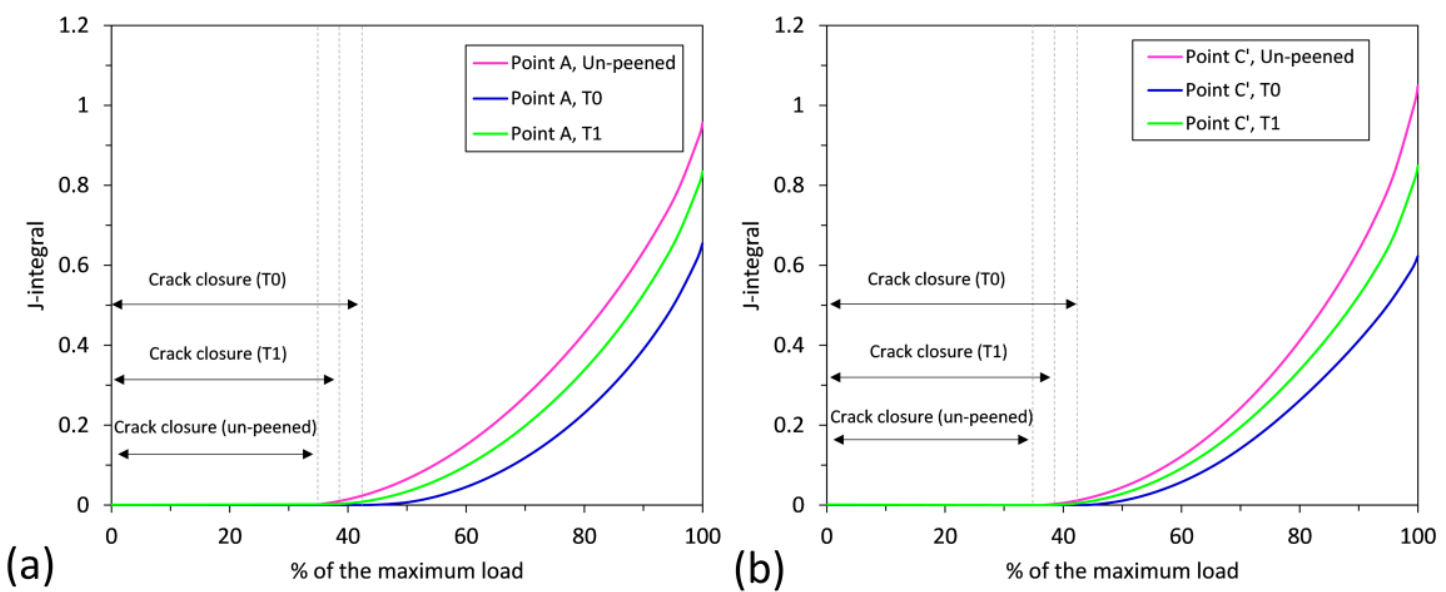

Fig. 16: J-integral evolution at (a) point $A$ and (b) point $C^{\prime}$ on the crack front ( $a=0.1 \mathrm{~mm}, a / c=0.8$ ) with increasing load.

The process of calibrating the closed-form solution, which describes the J-integral value at the maximum load $\left(U_{\max }\right)$ for cracks with various combination of $a$ and $a / c$, is expressed by Equation 3 5. This process was implemented for point $A$ and point $C^{\prime}$ under un-peened, T0 and T1 conditions separately. As the first step, the variation of $J_{\max }$ with $a$ was fitted using the polynomial relationship in Equation 3 at each fixed $a / c$, obtaining the corresponding fitting coefficients $B_{i}(i=1,2,3,4)$. Then, Equation 4 was calibrated to build up the relation between $B_{i}$ and $a / c$. Finally, Equation 5 was obtained by combining Equation 3 and 4 . The values of the calibrated parameters in Equation 5 , and the subsequent validation work are shown in Appendix A.

$J_{\max }(a)=B_{1} a+B_{2} a^{2}+B_{3} a^{3}+B_{4} a^{4}$

$B_{i}\left(\frac{a}{c}\right)=D_{i 0}+D_{i 1} \frac{a}{c}+D_{i 2}\left(\frac{a}{c}\right)^{2}+D_{i 3}\left(\frac{a}{c}\right)^{3} \quad(i=1,2,3,4)$

$J_{\max }\left(a, \frac{a}{c}\right)=\sum_{i=1}^{4}\left[D_{i 0}+D_{i 1} \frac{a}{c}+D_{i 2}\left(\frac{a}{c}\right)^{2}+D_{i 3}\left(\frac{a}{c}\right)^{3}\right] a^{i} \quad(i=1,2,3,4)$

The growth of the crack in the depth direction and at the surface are described using Equation 6 and 7 respectively, where $\Delta K_{e f f}\left(\Delta K_{e f f, A}\right.$ for the crack in the depth direction, $\Delta K_{e f f, C}$, for the surface crack) is used instead of $\Delta K$ in the Paris Law. The coefficients $C$ and $m$ were determined to be $C=$ $1.66 \times 10^{-9} \mathrm{~mm} \mathrm{cycle}^{-1}$ and $m=3.3$ [54]. The relative difference between crack growth in the two 
directions is described in Equation 8, which was obtained by combining Equations 6 and 7. Based on Equation 8 , crack advance at the surface $(d c)$ from a known crack shape was predicted by specifying an appropriate crack advance in the depth direction $(d a)$. Then a new crack front was obtained by connecting the updated points $A$ and $C^{\prime}$ using the semi-elliptical assumption of the crack front. Thus, the crack shape evolution was predicted by cyclically repeating this process with an initial (pre-defined) crack. Convergent results were obtained at $d a=0.002 \mathrm{~mm}$.

$\frac{d a}{d N}=C \Delta K_{e f f, A}^{m}$

$\frac{d c}{d N}=C \Delta K_{e f f, C^{\prime}}^{m}$

$\frac{d a}{d N} / \frac{d c}{d N}=\left(\frac{\Delta K_{e f f, A}}{\Delta K_{e f f, C l}}\right)^{m}$

In order to appropriately define the initial crack used in the prediction, the difference in crack initiation sites between the three surface conditions, as shown in Fig. 8, was interpreted by modelling a sharper crack ( $a=0.05 \mathrm{~mm}, a / c=1.2$ ), which represented a small crack initiating from inclusions. $\Delta K_{e f f}$ was obtained under the three surface conditions and the results are presented in Fig. 17. It can be seen that the reduction of $\Delta K_{\text {eff }}$ by the TO process is more pronounced than by the T1 process, implying that the TO process is more effective in resisting crack initiation from the inclusions. This conclusion is consistent with experimental observations in Fig. 8. In the modelling work, due to the varying crack initiation mechanism illustrated in Fig. 8, sharper $(a / c=1.2)$ and shallower $(a / c=0.2)$ initial cracks were chosen for the un-peened and TO conditions respectively. In the T1 condition, both types of initial cracks were modelled because of its combined crack initiation behaviour.

Comparison between the experimental data (reproduced from Fig. 5) and the prediction results are shown in Fig. 18. Generally speaking, the trend of the experimental data has been successfully predicted. Various initial crack configurations (indicated by the bracketed $a$ and $a / c$ values in the legend of each plot) were defined in the prediction to examine the scatter band of the experimental results. In the un-peened condition shown in Fig. 18(a)(b), with the initial $a$ values set between 0.035 $<a<0.068 \mathrm{~mm}$, the experimental crack data in the early stages of growing were found to be well bounded by the prediction. The equilibrium state of the crack shape was predicted to be $a / c=0.85$, which was slightly lower than the experimental observation $(a / c=0.93)$. In the T0 condition shown in Fig. 18(c)(d), apart from the data representing crack coalescence, most experimental data stay within the scatter band determined by the prediction with the initial $a$ values set between $0.012<a<0.019$ $\mathrm{mm}$. One exception is the data point representing the shortest crack, which was expected to develop from an initial crack with smaller $a$ or $a / c$, being outside the scope defined for this modelling work. It can also be observed that the $a / c$ value begins to increase with growing crack sizes, after being 
relatively stable $(a / c=0.83)$ at $a=0.15-0.2 \mathrm{~mm}$. This phenomenon, which was not observed in the un-peened condition, can be attributed to the CRS induced by the TO shot peening. According to Fig. 10 , the CRS in the TO condition starts to decrease sharply when $z>0.2 \mathrm{~mm}$, implying the degradation of the beneficial effects from the TO process on crack advance at point A when $a>0.2 \mathrm{~mm}$. Meanwhile, the surface crack is still embedded in the CRS field, implying that the crack advance at point $C^{\prime}$ is still retarded by shot peening. Therefore, when $a>0.2 \mathrm{~mm}$, cracks tend to grow quicker in the depth direction than at the surface, resulting in an increase in $a / c$. Results for the T1 condition are shown in Fig. 18(e)(f). Again, both crack growth features were reasonably predicted by setting the initial $a$ between $0.01<a<0.032 \mathrm{~mm}$ (initial $a / c=1.2$ ) and $0.01<a<0.025 \mathrm{~mm}$ (initial $a / c=0.2$ ) respectively. Similarly with the TO condition, the experimental data outside the determined scatter band were probably caused by shallower or shorter initial cracks (i.e. $a<0.01$ or $a / c<0.2$ ). In spite of the various initial crack configurations, a converged $a / c$ value is achieved between $0.91-0.97$.
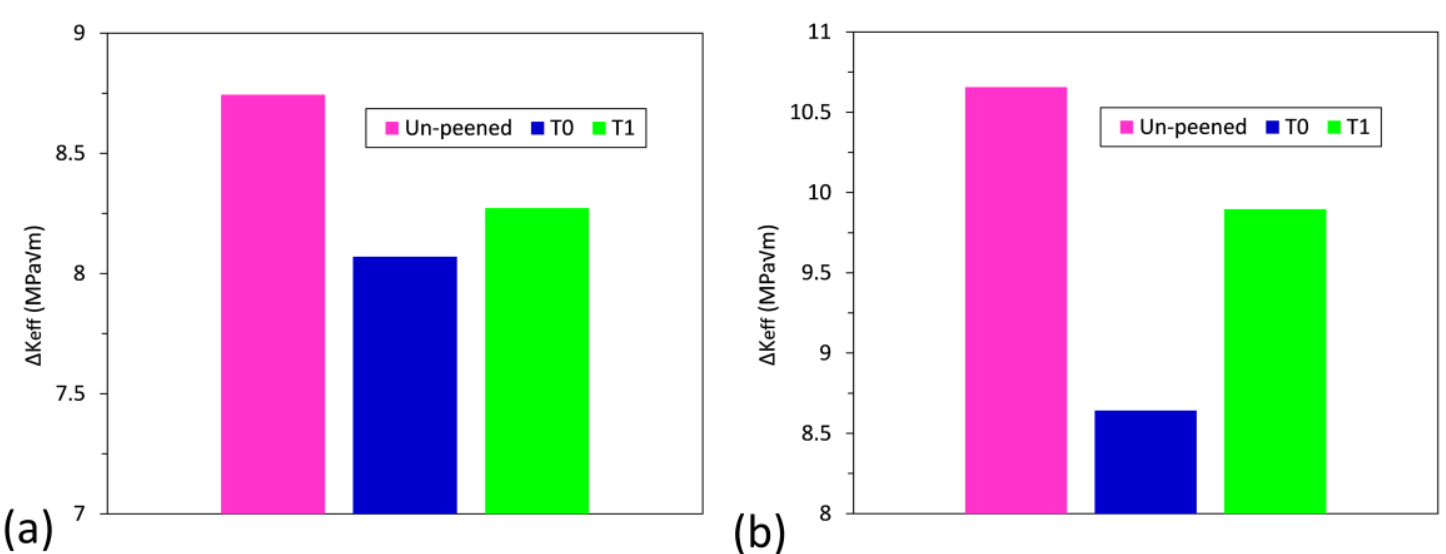

(b)

Fig. 17: Comparison between $\Delta K_{\text {eff }}(a=0.05 \mathrm{~mm}, a / c=1.2)$ under varying surface conditions at (a) point $A$ and $(b)$ point $C^{\prime}$. The initial cracks defined in Fig. 18 were supposed to appear at the very early stages of crack growth, shortly after crack initiation. The crack initiation stage was negligible in this study because the surface (or near surface) stress concentration sites, which were caused by the notch geometry, the inclusions or surface crack-like imperfections introduced by shot peening, are always responsible for the rapid formation of a surface crack $[12,13,17]$. The size and shape of these initial cracks are directly related to the configuration of the pre-existing defects. The determined scatter band in Fig. 18 can be used to quantitatively evaluate the effects of the size and shape of initial cracks on the crack growth behaviour. 



Fig. 18: Comparison between the predicted crack shape evolution with experimental results in (a)(b) un-peened, (c)(d) TO and $(e)(f) T 1$ conditions: $(a)(c)(d) a / c$ vs $a,(b)(d)(f) a / c$ vs $c$. The bracketed $a$ and $a / c$ values in the legend of each plot refer to the initial crack shape used in the prediction.

\subsection{Prediction of crack growth}

The crack growth behaviour ( $c$ vs $N, a$ vs $N$ ) has been predicted using the Paris Law (Equation 6 and 7), taking the effects of crack shape evolution into account. The $a$ and $a / c$ values of the initial crack, which were determined to define the experimental scatter band in Fig. 18, have been used in this prediction as the configuration of the initial crack. As stated in Section 3.3, the crack initiation process was not considered in this prediction. Due to the limitation of the model, the prediction was carried out up to a crack depth of $a=0.4 \mathrm{~mm}$, the corresponding surface crack length $(2 c)$ was determined based on the predicted $a / c$. 
The predicted surface crack growth ( $c$ vs $N$ ) results are compared with experimental data reproduced from Fig. 5, as shown in Fig. 19. Decent prediction results have been obtained for the un-peened (Fig. 19(a)) and TO (Fig. 19(b)) conditions, although the experimental results for the T0 condition seem more scattered due to the presence of several parallel cracks. However, in the T1 condition displayed in Fig. 19(c), the prediction results display a clear deviation from the experimental data; the prediction seems non-conservative regardless of the initial crack configurations. This mismatch might be attributed to the complicated crack initiation mechanism in the T1 condition (Fig. 8(c)(d)), which adds more difficulty in accurately predicting the crack shape, especially when potential crack coalescence happens.



(a)

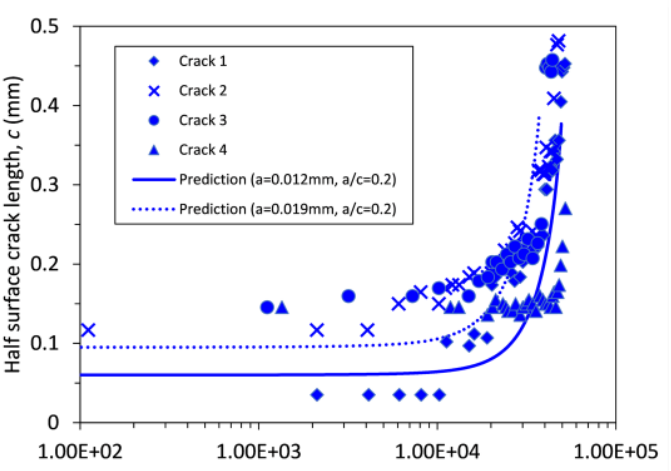

(b)

No. of cycles

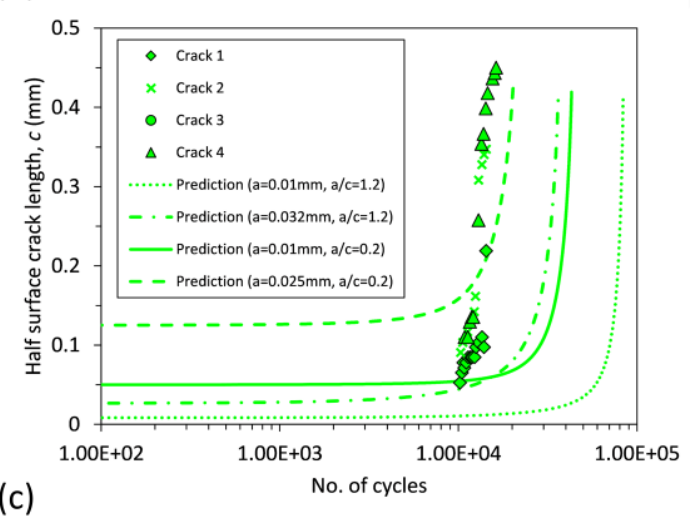

Fig. 19: Comparison between the predicted surface crack growth and the corresponding experimental results in the (a) unpeened, (b) TO and (c) T1 shot peening conditions. The bracketed $a$ and a/c values in the legend of each plot refer to the initial crack shape used in the prediction. 
The predicted crack growth in the depth direction ( $a$ vs $N$ ) was also obtained, as shown in Fig. 20. In addition, the prediction relying on a previous plane strain 2D FE model [32] has been carried out as a comparison with the 3D modelling results, using the same initial $a$ with the 3D model. According to Fig. 20, a longer crack growth process is always predicted using the $3 \mathrm{D}$ model than the $2 \mathrm{D}$ model, in spite of different surface conditions. This discrepancy can be attributed to the neglect of the effects of crack shape on the crack driving force in the 2D model. As described in Fig. 21, when the depth of the crack (a) maintains unchanged, the obtained $\Delta K_{\text {eff }}$ from the 3D FE model at point $\mathrm{A}$ increases with decreasing $a / c$, approaching the $2 \mathrm{D} \mathrm{FE}$ modelling results. This is unsurprising since the 2D crack represents a through-thickness crack with an $a / c$ effectively approaching zero, which is lower than the $a / c$ of any 3D semi-elliptical crack. The same trend can be found in the un-peened, T0 and T1 conditions. Consequently, the overestimated crack driving force from the 2D FE model resulted in a more underestimated crack growth life compared with the 3D FE modelling results (Fig. 20).

In addition, Fig. 20(c) also shows a clear difference between the predicted crack growth life resulting from two diverse initial crack configurations (although with identical crack depth) in the T1 condition. The reasons accounting for this difference have been investigated. Fig. 22(a) shows that the shallower initial crack $(a / c=0.2)$ leads to a higher $\Delta K_{\text {eff }}$ (hence shorter life) compared with the sharper initial $\operatorname{crack}(a / c=1.2)$, until the crack grows to $a=0.15 \mathrm{~mm}$. The crack shape evolution process under both circumstances is schematically illustrated in Fig. 22(b), demonstrating an equilibrium state of the crack shape at $a=0.15 \mathrm{~mm}$. This analysis, once more, emphasised the necessity of considering the role of the crack shape during short crack growth investigations.

To further understand the effects of shot peening, crack growth from the identical initial crack configuration under different surface treatments (un-peened, T1 and T0) has been numerically investigated. The initial crack was set as $a=0.035 \mathrm{~mm}$ and $a / c=1.2$, which represented the lower bound of the initial cracks nucleated from the inclusions in the un-peened condition, as shown in Fig. 19(a). Fig. 23(a) depicts the predicted crack growth behaviour in the depth direction ( $a$ vs $N$ ). Clearly, shot peening retards the short crack growth behaviour, and the TO process is more effective than the $\mathrm{T} 1$ process. The associated $\Delta K_{e f f}$ values at point $\mathrm{A}$ of a growing crack have also been obtained, as shown in Fig. 23(b). This demonstrates a more evident reduction in the crack driving force resulting from the T0 process than the T1 process, which accounts for the difference between the two shot peening processes shown in Fig. 23(a). Although this numerical analysis is perhaps less consistent with reality since no inclusion-induced crack initiation was experimentally observed in the TO condition, it intuitively demonstrates the shot peening effects in decelerating the crack growth rate apart from any effects on the crack initiation mechanism. Additionally, despite the fact that the initial crack configurations applied under different surface treatment conditions are identical, the results 
presented in Fig. 23 inherently involves different crack shape evolution processes, which accounts for the main difference with the $2 \mathrm{D}$ modelling results shown in [32].

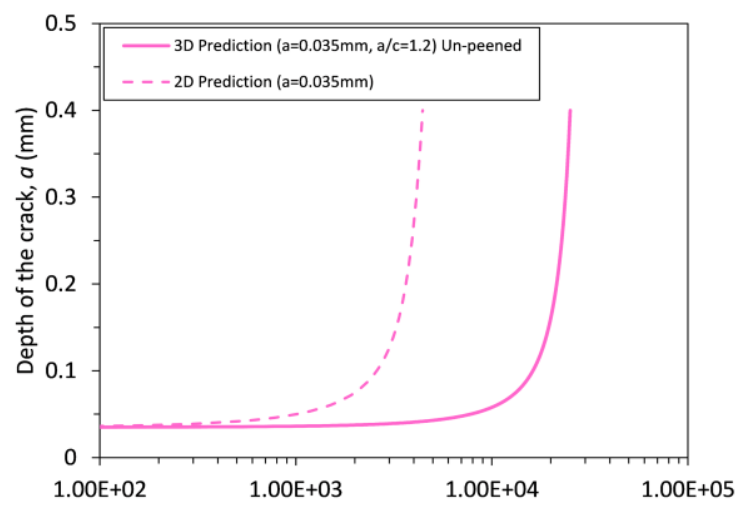

(a)

No. of cycles

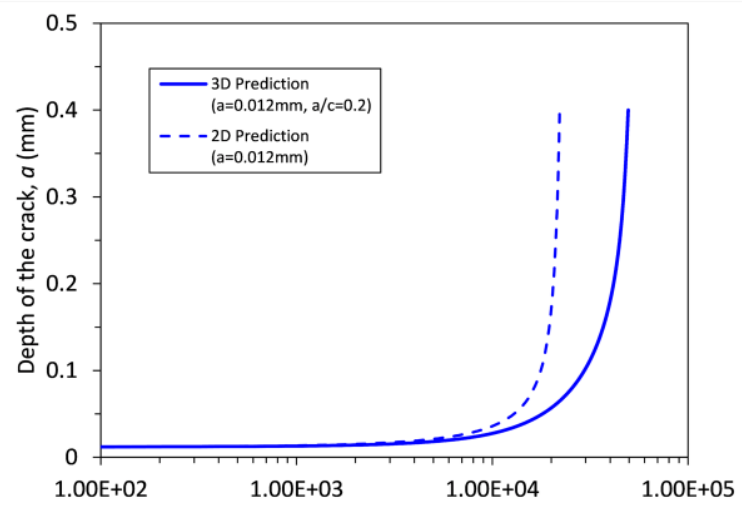

(b)

No. of cycles

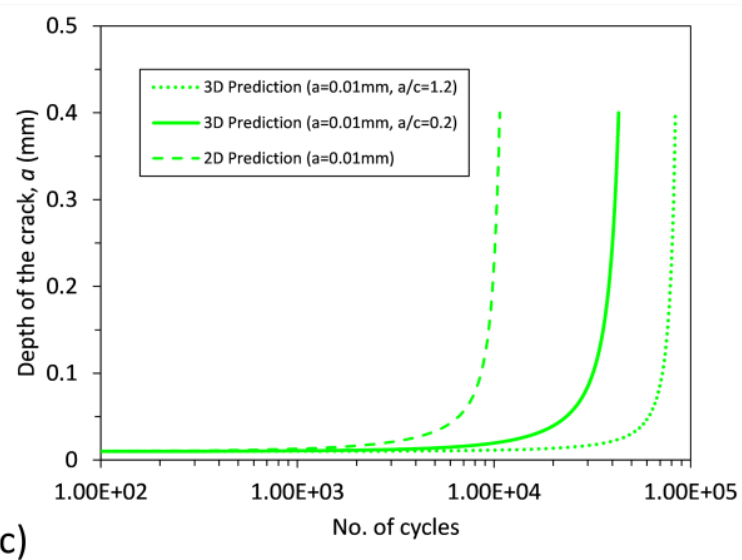

Fig. 20: Comparison between the predicted crack growth behaviour in the depth direction (a vs N) using 3D and 2D FE models in the (a) un-peened, (b) TO and (c) T1 conditions. The bracketed $a$ and a/c values in the legend of each plot refer to the initial crack shape (3D) or size (2D) used in the prediction. 




(a)

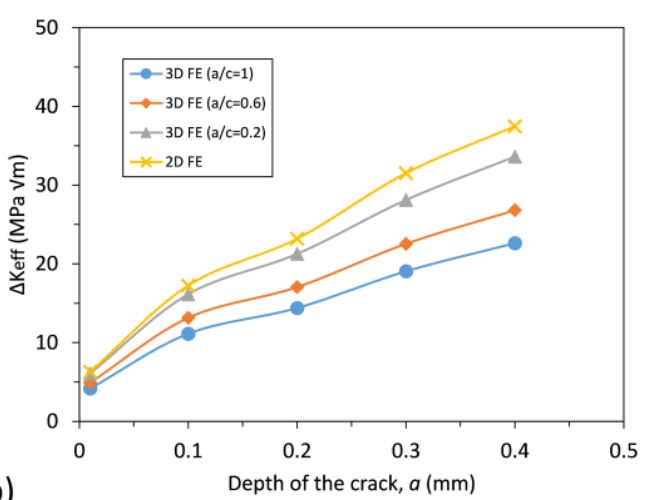

(b)

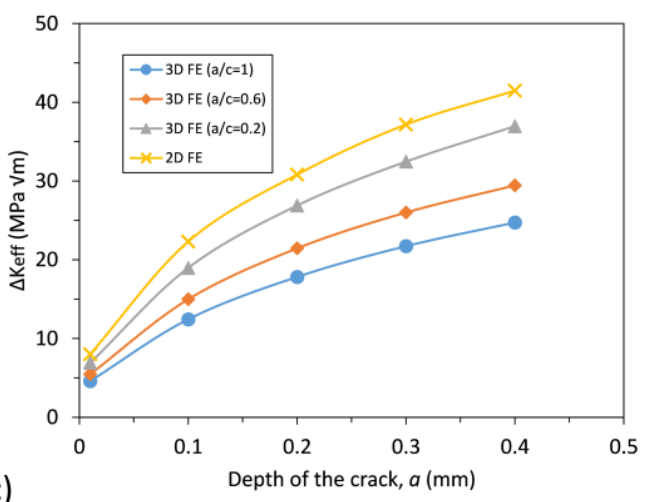

Fig. 21: Comparison between the $\Delta K_{\text {eff }}$ at point $A$ of the crack front with varying a/c values in the (a) un-peened, (b) TO and (c) $T 1$ conditions.


(b)

Fig. 22: The difference resulting from two initial crack configurations in (a) $\Delta K_{\text {eff }}$ at point $A$ and (b) crack shape evolution. The bracketed $a$ and $a / c$ values in the legend of each plot refer to the initial crack shape used in the prediction. 

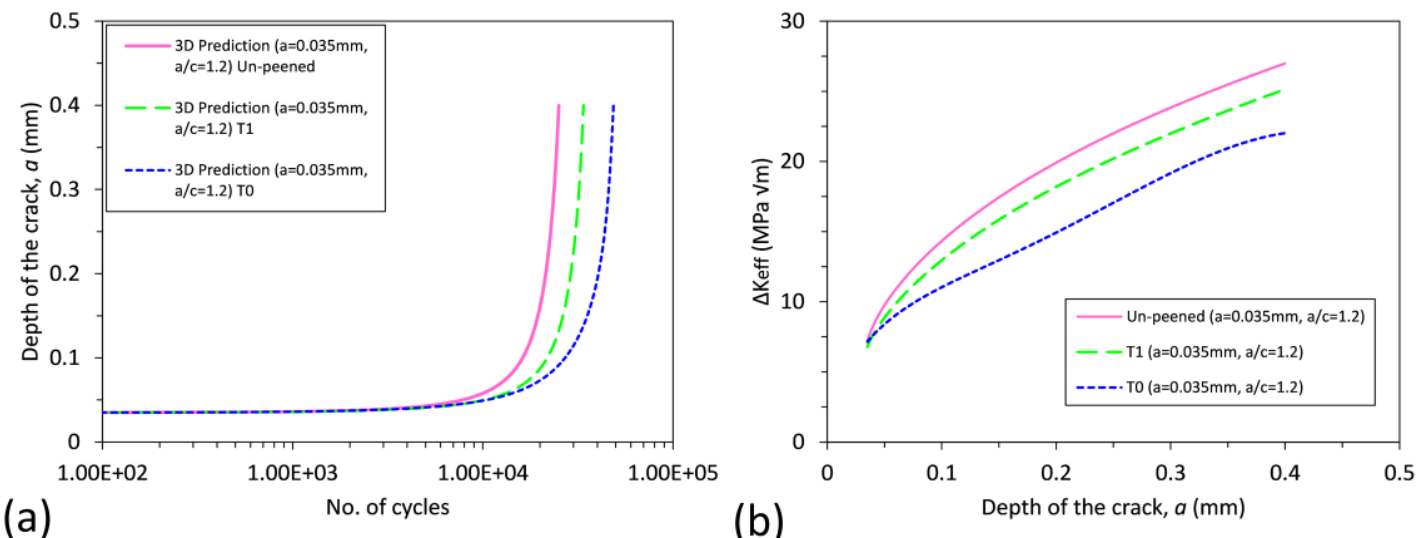

Fig. 23: The difference resulting from surface treatments in (a) the predicted crack growth behaviour in the depth direction ( $a$ vs $N$ ) with the identical initial crack configuration $(a=0.035 \mathrm{~mm}, a / c=1.2)$, and (b) the associated $\Delta K_{\text {eff }}$ at point $A$.

\section{Discussion}

Through comparing the T0 (high peening intensity) and T1 (low peening intensity) shot peening processes, it can be confirmed that crack initiation from the perpendicular stringer inclusions, which is the main initiation mechanism in the un-peened condition, is more likely to be resisted by a more intense CRS field because of the reduced crack driving force (Fig. 17). It is also advantageous to produce a deeper CRS field to expand the influence of shot peening in terms of the depth through which the crack growth is delayed (Fig. 14). From this point, a high peening intensity, which may result in a greater and deeper CRS field, is beneficial. However, high peening intensity is also likely to increase the surface roughness, or to introduce more surface defects, which may facilitate additional crack initiation and thus degrades the benefits of shot peening. Hence, with the same peening intensity, it is reasonable to expect a more prominent life improvement if the post-peening surface condition is ameliorated, and conversely, an unimproved (or even degraded) fatigue life if the post-peening surface is excessively roughened. Consequently, in order to more accurately quantify the influence of shot peening on fatigue life, a method capable of evaluating crack growth from different types of surface (or near surface) defects, would be helpful.

In the current modelling work, although the crack initiation process was not modelled nor predicted, the diversity in early crack configurations, which was directly related to the crack initiation mechanism caused by different surface (or near surface) defects, has been considered in the modelling work. It was found that the crack driving force depended on both the residual stress state and the crack shape, as shown in Fig. 17 and Fig. 21 respectively. Hence, neglecting the crack shape effects potentially may affect true estimation of shot peening effects on delaying short crack growth. This implies that the modelling methodology introduced in this study is promising to more accurately assess shot peening effects, especially when the remeshing technique is integrated in future work. It is also an important 
tool to use in optimising the shot peening process, where the trade-off between a greater CRS field and a more roughened post-peening surface (all resulting from a high peening intensity), is required.

\section{Conclusions}

In this study, a 3D FE model has been developed to investigate the short crack growth behaviour in a notched specimen subjected to shot peening. The compressive residual stress and strain hardening effects caused by shot peening have been incorporated into the model utilising the methods introduced in [22]. The following major conclusions have been demonstrated.

- Residual stress redistribution caused by both mechanical loading and crack advance has been modelled. The compressive residual stress distribution tends to be stable while the crack advances until the crack penetrates through the compressive residual stress field, confining residual stress redistribution to a small area near the crack front.

- Different crack initiation mechanisms were experimentally observed in the un-peened and shot-peened conditions, which resulted in diversity of the initial crack configuration and thus different crack shape evolution processes. Using the developed 3D FE model, crack shape evolution in both the un-peened and shot-peened conditions has been successfully predicted, with appropriately defined initial crack configurations.

- Surface crack growth ( $c$ vs $N$ ) has been successfully predicted in the un-peened and TO (high peening intensity) conditions, where crack initiation shows unique features respectively. In the T1 (low peening intensity) condition, $c$ vs $N$ was not reliably predicted due to the more complicated crack initiation mechanism.

- Compared with the 3D model, the prediction of short crack growth in the depth direction ( $a$ vs $N$ ) relying on the $2 \mathrm{D}$ model (with the plane strain assumption) underestimated the short crack growth life, as the 2D model does not consider the effects of crack shape.

\section{Acknowledgements}

Financial support from China Scholarship Council and the Engineering and Physical Sciences Research Council (EP/K503150/1) is gratefully acknowledged. The authors also acknowledge the support of the University of Southampton for access to its IRIDIS4 High Performance Computing Facility.

\section{Data access statement}

All data supporting this study are openly available from the University of Southampton repository at http://doi.org/10.5258/SOTON/D0099. 


\section{Appendix A. Calibration results and validation}

The values of the calibrated parameters in Equation 5 are shown in Table A1. It was found that an order of three for Equation 5 (i.e. $B_{4}=0$ ) was sufficient to ensure a good fitting accuracy for the unpeened and T1 conditions, while an order of four was required for the TO condition. Hence the values of $D_{4 j}(j=0,1,2$ and 3$)$ in Equation 5 are only available for the T0 condition, as shown in Table A1.

The quality of the fitting work was checked by comparing the FE-determined results, which were used as the "training" data, with corresponding predictions obtained using the calibrated Equation 5. Fig. A1 shows the comparison at point $A$ under the un-peened, T0 and T1 shot peening conditions, demonstrating a good fit. Similarly, a good fit was also obtained at point $C^{\prime}$, relevant results are not presented here for brevity. The applicability of the calibration of Equation 5 has been validated using additional "test" FE modelling results that were not used in the fitting work. Some of the validation results are shown in Fig. A2, demonstrating the reliability of the calibrated Equation 5 within the defined range $(0.01 \leq a \leq 0.4 \mathrm{~mm}, 0.2 \leq a / c \leq 1.2)$.

Table A1: Calibrated values of the parameters in Equation 5 for point $A$ and point $C^{\prime}$ under un-peened, TO and T1 conditions.

\begin{tabular}{ccccccc}
\hline \multirow{2}{*}{$D_{i j}$} & \multicolumn{2}{c}{ Un-peened } & \multicolumn{2}{c}{ T0 } & \multicolumn{2}{c}{ T1 } \\
\cline { 2 - 7 } & Point A & Point C' & Point A & Point C' & Point A & Point C' \\
\hline$D_{10}$ & 28.2 & 9.928 & 23.905 & 5.1225 & 22.342 & 9.8967 \\
$D_{11}$ & -42.274 & 12.965 & -26.093 & 8.1245 & -33.1 & -1.5095 \\
$D_{12}$ & 32.455 & -18.341 & 15.758 & -7.8109 & 25.811 & 1.1492 \\
$D_{13}$ & -10.172 & 6.547 & -4.074 & 1.9712 & -8.0663 & -0.7514 \\
$D_{20}$ & -37.799 & -22.81 & -147.05 & -6.5369 & -9.3678 & -32.275 \\
$D_{21}$ & 105.46 & 26.099 & 147.59 & -5.7683 & 54.801 & 96.483 \\
$D_{22}$ & -114.06 & -26.264 & -83.5 & -21.463 & -71.973 & -128.65 \\
$D_{23}$ & 43.591 & 12.447 & 20.547 & 18.399 & 28.853 & 52.252 \\
$D_{30}$ & 50.034 & 40.117 & 611.9 & 14.915 & 9.3024 & 55.935 \\
$D_{31}$ & 178.78 & 96.549 & -652.01 & -35.873 & 101.63 & -166.6 \\
$D_{32}$ & 218.61 & 120.06 & 399.57 & 97.236 & 149.76 & 231.56 \\
$D_{33}$ & -88.529 & -52.392 & -104.67 & -56.668 & -63.376 & -97.344 \\
$D_{40}$ & N/A & N/A & -724.09 & N/A & N/A & N/A \\
$D_{41}$ & N/A & N/A & 757.75 & N/A & N/A & N/A \\
$D_{42}$ & N/A & N/A & -446.66 & N/A & N/A & N/A \\
$D_{43}$ & N/A & N/A & 108.72 & N/A & N/A & N/A \\
\hline & & & & & &
\end{tabular}




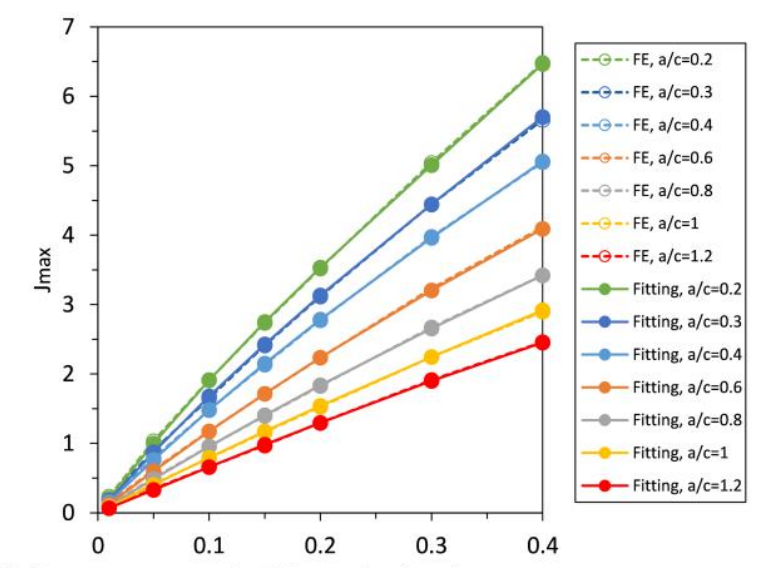

(a)

Depth of the crack, $a(\mathrm{~mm})$



(b)

Depth of the crack, $a(\mathrm{~mm})$



(c)

Depth of the crack, $a(\mathrm{~mm})$

Fig. A1: Comparison of the FE-determined $J_{\text {max }}$ at point A with corresponding fitted predictions under (a) un-peened, (b) TO and (c) T1 conditions. 


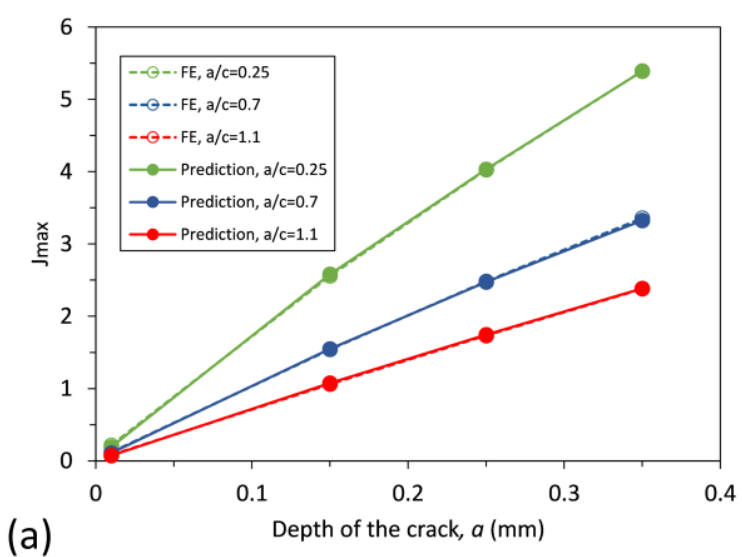

(a)



(b)

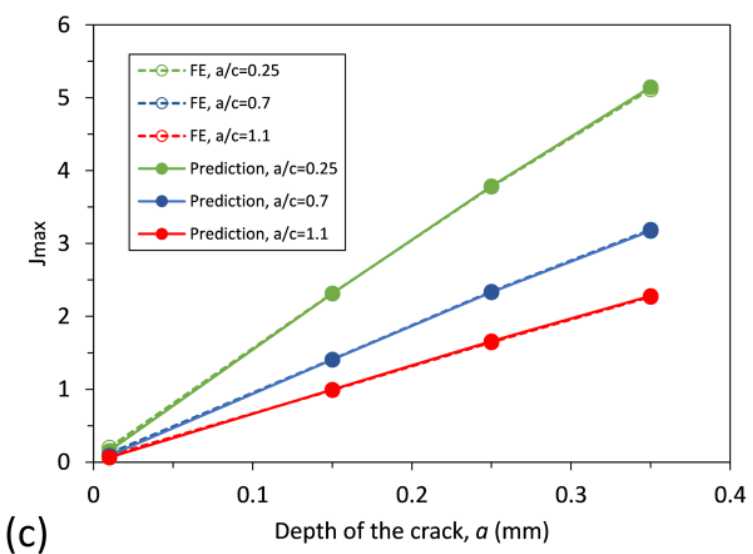

Fig. A2: Validation of the fitting approach by comparing the FE-determined $J_{\max }$ at point $A$ with corresponding predicted results using the calibrated Equation 5, under (a) un-peened, (b) TO and (c) T1 conditions. Note this FE data was not used to determine the fitting equation.

\section{References}

1. James, M.N., et al., Shot-peening of steam turbine blades: Residual stresses and their modification by fatigue cycling. Procedia Engineering, 2010. 2(1): p. 441-451.

2. Newby, M., M.N. James, and D.G. Hattingh, Finite element modelling of residual stresses in shot-peened steam turbine blades. Fatigue \& Fracture of Engineering Materials \& Structures, 2014. 37(7): p. 707-716.

3. Soady, K.A., et al., The effect of shot peening on notched low cycle fatigue. Materials Science and Engineering: A, 2011. 528(29-30): p. 8579-8588. 
4. AlMangour, B. and J.-M. Yang, Improving the surface quality and mechanical properties by shot-peening of 17-4 stainless steel fabricated by additive manufacturing. Materials \& Design, 2016. 110: p. 914-924.

5. Rios, E.R.d.I., et al., Fatigue crack initiation and propagation on shot-peened surfaces in A316 stainless steel. International Journal of Fatigue, 1995. 17(7): p. 493-499.

6. Dalaei, K. and B. Karlsson, Influence of shot peening on fatigue durability of normalized steel subjected to variable amplitude loading. International Journal of Fatigue, 2012. 38: p. 75-83.

7. Kim, J.-C., S.-K. Cheong, and H. Noguchi, Residual stress relaxation and low-and high-cycle fatigue behavior of shot-peened medium-carbon steel. International Journal of Fatigue, 2013. 56: p. 114-122.

8. Wagner, L., Mechanical surface treatments on titanium, aluminum and magnesium alloys. Materials Science and Engineering: A, 1999. 263(2): p. 210-216.

9. Černý, I., J. Sís, and D. Mikulová, Short fatigue crack growth in an aircraft Al-alloy of a 7075 type after shot peening. Surface and Coatings Technology, 2014. 243: p. 20-27.

10. González, J., et al., Influence of different shot peening treatments on surface state and fatigue behaviour of Al 6063 alloy. Engineering Fracture Mechanics, 2017.

11. Benedetti, M., et al., Notch fatigue behaviour of shot peened high-strength aluminium alloys: Experiments and predictions using a critical distance method. International Journal of Fatigue, 2010. 32(10): p. 1600-1611.

12. Rios, E.R.D.L., M. Trull, and A. Levers, Modelling fatigue crack growth in shot-peened components of Al 2024-T351. Fatigue \& Fracture of Engineering Materials and Structures, 2000. 23(8): p. 709-716.

13. Gao, Y.K. and X.R. Wu, Experimental investigation and fatigue life prediction for 7475-T7351 aluminum alloy with and without shot peening-induced residual stresses. Acta Materialia, 2011. 59(9): p. 3737-3747.

14. Barry, N., S.V. Hainsworth, and M.E. Fitzpatrick, Effect of shot peening on the fatigue behaviour of cast magnesium A8. Materials Science and Engineering: A, 2009. 507(1-2): p. 50-57.

15. Song, X., et al., An eigenstrain-based finite element model and the evolution of shot peening residual stresses during fatigue of GW103 magnesium alloy. International Journal of Fatigue, 2012. 42: p. 284-295.

16. Zhuang, W.Z. and G.R. Halford, Investigation of residual stress relaxation under cyclic load. International Journal of Fatigue, 2001. 23: p. 31-37.

17. Cláudio, R.A., et al., Failure analysis of scratch damaged shot peened simulated components at high temperature. Engineering Failure Analysis, 2009. 16(4): p. 1208-1220.

18. He, B.Y., et al., Fatigue crack growth behaviour in the LCF regime in a shot peened steam turbine blade material. International Journal of Fatigue, 2016. 82: p. 280-291.

19. Soady, K.A., Life assessment methodologies incoroporating shot peening process effects: mechanistic consideration of residual stresses and strain hardening Part 1 - effect of shot peening on fatigue resistance. Materials Science and Technology, 2013. 29(6): p. 637-651.

20. Soady, K.A., B.G. Mellor, and P.A.S. Reed, Life assessment methodologies incoroporating shot peening process effects: mechanistic consideration of residual stresses and strain hardening Part 2 - approaches to fatigue lifing after shot peening. Materials Science and Technology, 2013. 29(6): p. 652-664.

21. Soady, K.A., et al., Evaluating surface deformation and near surface strain hardening resulting from shot peening a tempered martensitic steel and application to low cycle fatigue. International Journal of Fatigue, 2013. 54: p. 106-117.

22. You, C., et al., Low cycle fatigue life prediction in shot-peened components of different geometries - Part I: Residual stress relaxation. Fatigue \& Fracture of Engineering Materials \& Structures, 2017. 40(5): p. 761-775.

23. Buchanan, D.J. and R. John, Residual stress redistribution in shot peened samples subject to mechanical loading. Materials Science and Engineering: A, 2014. 615: p. 70-78. 
24. You, C., et al., Low cycle fatigue life prediction in shot-peened components of different geometries - Part II: Life prediction. Fatigue \& Fracture of Engineering Materials \& Structures, 2017. 40(5): p. 749-760.

25. Benedetti, M., V. Fontanari, and M. Bandini, $A$ simplified and fast method to predict plain and notch fatigue of shot peened high-strength aluminium alloys under reverse bending. Surface and Coatings Technology, 2014. 243: p. 2-9.

26. Gérin, B., et al., Competition between surface defects and residual stresses on fatigue behaviour of shot peened forged components. Procedia Structural Integrity, 2016. 2: p. 32263232.

27. Kim, J.-C., S.-K. Cheong, and H. Noguchi, A non-microstructural crack formation model for understanding fatigue life degradation in shot peened carbon steel under LCF loading. International Journal of Fatigue, 2014. 63: p. 110-117.

28. Terres, M.A., N. Laalai, and H. Sidhom, Effect of nitriding and shot-peening on the fatigue behavior of 42CrMo4 steel: Experimental analysis and predictive approach. Materials \& Design, 2012. 35: p. 741-748.

29. Dalaei, K., B. Karlsson, and L.E. Svensson, Stability of shot peening induced residual stresses and their influence on fatigue lifetime. Materials Science and Engineering: A, 2011. 528(3): p. 1008-1015.

30. Torres, M.A.S. and H.J.C. Voorwald, An evaluation of shot peening, residual stress and stress relaxation on the fatigue life of AISI 4340 steel. International Journal of Fatigue, 2002. 24(8): p. 877-886.

31. Lin, B., et al., Fatigue crack growth in laser-shock-peened Ti-6Al-4V aerofoil specimens due to foreign object damage. International Journal of Fatigue, 2014. 59: p. 23-33.

32. You, C., et al., A numerical study of the effects of shot peening on the short crack growth behaviour in notched geometries under bending fatigue tests. International Journal of Fatigue, 2017. 103: p. 99-111.

33. He, B.Y., et al., 3-D analysis of fatigue crack behaviour in a shot peened steam turbine blade material. Materials Science and Engineering: A, 2015. 642: p. 91-103.

34. He, B., Fatigue crack growth behaviour in a shot peened low pressure steam turbine blade material. 2015, University of Southampton.

35. Carpinteri, A., Shape change of surface cracks in round bars under cyclic axial loading. International Journal of Fatigue, 1993. 15(1): p. 21-26.

36. Lin, X.B. and R.A. Smith, Finite element modelling of fatigue crack growth of surface cracked plates Part II Crack shape change. Engineering Fracture Mechanics, 1999. 63(5): p. 523-540.

37. Achintha, M., et al., Eigenstrain modelling of residual stress generated by arrays of laser shock peening shots and determination of the complete stress field using limited strain measurements. Surface and Coatings Technology, 2013. 216: p. 68-77.

38. Zabeen, S., M. Preuss, and P.J. Withers, Evolution of a laser shock peened residual stress field locally with foreign object damage and subsequent fatigue crack growth. Acta Materialia, 2015. 83: p. 216-226.

39. Branco, R., et al., Extent of surface regions near corner points of notched cracked bodies subjected to mode-l loading. Finite Elements in Analysis and Design, 2012. 50: p. 147-160.

40. Hou, C.-Y., Three-dimensional finite element analysis of fatigue crack closure behavior in surface flaws. International Journal of Fatigue, 2004. 26(11): p. 1225-1239.

41. Daniewicz, S.R. and C.R. Aveline, Strip-yield and finite element analysis of part-through surface flaws. Engineering Fracture Mechanics, 2000. 67: p. 21-39.

42. Gardin, C., et al., Numerical prediction of crack front shape during fatigue propagation considering plasticity-induced crack closure. International Journal of Fatigue, 2016. 88: p. 6877. 
43. Predan, J., V. Močilnik, and N. Gubeljak, Stress intensity factors for circumferential semielliptical surface cracks in a hollow cylinder subjected to pure torsion. Engineering Fracture Mechanics, 2013. 105: p. 152-168.

44. Shin, C.S. and C.Q. Cai, Experimental and finite element analyses on stress intensity factors of an elliptical surface crack in a circular shaft under tension and bending. International Journal of Fracture, 2004. 129(3): p. 239-264.

45. Hou, C.-Y., Simulation of surface crack shape evolution using the finite element technique and considering the crack closure effects. International Journal of Fatigue, 2011. 33(5): p. 719-726.

46. Ferrié, E., et al., Fatigue crack propagation: In situ visualization using X-ray microtomography and 3D simulation using the extended finite element method. Acta Materialia, 2006. 54(4): p. 1111-1122.

47. Carpinteri, A., R. Brighenti, and S. Vantadori, Influence of the cold-drawing process on fatigue crack growth of a V-notched round bar. International Journal of Fatigue, 2010. 32(7): p. 11361145.

48. Burke-Veliz, A., S. Syngellakis, and P.A.S. Reed, Assessment of three-dimensional crack growth in ductile layered material systems. Engineering Fracture Mechanics, 2012. 88: p. 15-27.

49. Branco, R., F.V. Antunes, and J.D. Costa, A review on 3D-FE adaptive remeshing techniques for crack growth modelling. Engineering Fracture Mechanics, 2015. 141: p. 170-195.

50. Newman, J.C. and I.S. Raju, An empirical stress-intensity factor equation for the surface crack. Engineering fracture mechanics, 1981. 15(1-2): p. 185-192.

51. Smyth, N., Effect on Fatigue Performance of Residual Stress induced via Laser Shock Peening in Mechanically Damaged 2024 - T351 Aluminium Sheet, in School of Applied Science. 2014, Cranfield University: Cranfield.

52. Pavier, M.J., C.G.C. Poussard, and D.J. Smith, Effect of residual stress around cold worked holes on fracture under superimposed mechanical load. Engineering Fracture Mechanics, 1999. 63(6): p. 751-773.

53. Lei, Y., J calculation for a crack in a welding residual stress field following a FE welding simulation. Trans SMiRT, 2015. 23.

54. Soady, K.A., Reducing conservatism in life assessment approaches: Industrial steam turbine blade to disc interfaces and the shot peening process, in University of Southampton. 2013. 